\title{
INTRODUCED FISH ASSEMBLAGES IN A MOSAIC OF URBAN PONDS: EVIDENCE FOR SPECIES-AREA AND DIVERSITY-DOMINANCE PATTERNS
}

\author{
Corrado Battistia,", Maria Paola Di Santo ${ }^{b}$, Luca Luiselli ${ }^{c, d}$, Giovanni Amorie ${ }^{\text {, }}$, and Giuseppe M. Carpaneto ${ }^{f}$
}

\begin{abstract}
a“"Torre Flavia” LTER(Long Term Ecological Research) Station, Città Metropolitana di Roma Capitale - Servizio Aree protette - Parchi regionali, via Tiburtina 691, 00159 Rome, Italy; ${ }^{b}$ via Michele Saponaro, 10-00143 Rome, Italy; 'IDECC, Institute for Development, Ecology, Conservation and Cooperation, via G. Tomasi di Lampedusa 33, 00144 Rome, Italy; ${ }^{\mathrm{d}}$ Department of Applied and Environmental Biology, Rivers State University of Science and Technology, PMB 5080, Port Harcourt, Rivers State, Nigeria; ${ }^{\mathrm{e}} \mathrm{CNR}$ Institute of Ecosystem Studies, via dell’Università, 32, 00185 Rome, Italy; fDipartimento di Scienze, Università Roma Tre, viale G. Marconi, 446, 00146 Rome, Italy *Corresponding author. Email: c.battisti@cittametropolitanaroma.gov.it
\end{abstract}

\section{Article history Received: 18 February 2020; accepted 12 October 2020}

Keywords: Urban ecology; Whittaker plots; introduction; extinction; Rome; Italy

\begin{abstract}
We studied species-area and diversity-dominance patterns in fish communities of a mosaic of urban ponds (Rome, Italy). We detected 10 fish species (all introduced) in 40 isolated ponds $(12.9 \%$ of the total; $\mathrm{n}=311)$. The $\log$-transformed species-area relationship $(\log \mathrm{S}=0.04 \log \mathrm{A}+$ 0.16) was significant. Assuming the lack of mechanisms of natural immigration between totally isolated ponds, the number of fish species in this mosaic of ponds may depend exclusively on progressive extinctions and on random and arbitrary events of introduction (acting as human-mediated immigration), these latter explaining the apparently low taxon-related isolation indicated by a low $z$ value $(=0.04)$. We observed a significantly lower number of species in the smallest ponds and a further threshold under 1 ha in size: these values could represent an interesting threshold for pond management. The diversity-dominance approach evidenced pond size effect acting as a factor of stress on these assemblages.
\end{abstract}

\section{INTRODUCTION}

The species-area relationship has been studied in many taxa both in geographic and ecological islands (MacArthur and Wilson 1967; Kalmar and Currie 2006), including human-made habitats (Watling and Donnelly 2006). Among the most important predictive processes explaining the decrease in the number of species with area reduction, the extinction mechanisms related to area size per se, habitat availability and isolation (sensu lato as a distance from the source of colonization; Boecklen 1986; Báldi 2008; Stein et al. 2014) should be mentioned. Under a given threshold of habitat size, viable populations of species gradually tend to develop towards extinction (Soule and Simberloff 1986). At community level, these progressive extinctions induce reduction in species richness correlated with area size decrease (MacArthur and Wilson 1967).

In urbanized landscapes, artificial ponds can be assimilated with islands of different size and isolation (Martınez-Arroyo and Jauregui 2000), with interesting implication in nature reserve management and biological conservation (e.g. Kitchener et al. 1980). These artificial ecosystems can host peculiar biological communities composed of both native and introduced species (Hassall 2014; Hill et al. 2017). In these contexts, immigration/extinction or introduction/extinction dynamics at different scales may explain the observed patterns of species richness, with pond size being the most important predictor (Godefroid and Koedam 2003; see also Oberdorff et al. 2011). However, how species respond to a pond size-induced stress is still poorly known (Leibowitz 2003; Benassi et al. 2007; Di Santo et al. 2015).

In this paper we would analyze the species-area pattern of totally introduced fish assemblages in a mosaic of artificial ponds of different size through an extensive urbanized landscape of a Mediterranean metropolitan area, the city of Rome. Following the general model (MacArthur and Wilson 1967), we predict that small (and isolated) ponds will have fewer species than large ones. Moreover, we hypothesize that a threshold size could exist under which species richness should abruptly decrease. However, since our target was a suite of introduced fish species (see Di Santo et al. 2017), we suggested the hypothesis that this pattern could be explained by random introduction/extinction dynamics more than by classic and deterministic immigration/ extinction processes. Moreover, since habitat size has been identified as a factor of stress inducing the disruption of the structure of animal communities (e.g. for birds: Battisti et al. 2009), we hypothesized that this phenomenon could be extended also to our introduced fish assemblages in urban ponds. In this regard, we used both a numerical approach (using diversity indices) and 
a graphical one, performing a species rank-frequency diagram (or diversity-dominance approach: Magurran 2004) to detect structural changes in introduced fish assemblages. The application of species-area and diversity-dominance relationships to introduced taxa of totally isolated artificial wet habitats may represent a case study in applied biogeography (Spellerberg and Sawyer 1999).

\section{MATERIALS AND METHODS}

\section{Study area}

The study area corresponds to the Rome metropolitan area (Italy) and covers an area of about 36,000 ha (48\%: green areas; $46 \%$ : building areas; 6\%: alluvial areas). Climate is thermo-mediterranean. A mosaic of 311 artificial urban ponds (hereafter, AUPs) embedded in a continuous urbanized matrix were identified (total area: $32.93 \mathrm{ha}$ ), basing our selection on a regional map (scale 1:10,000) and satellite images (Google Earth 5.1). We used the term 'mosaic' as a 'pattern of interspersed ecosystems' (see Zhang et al. 2013; Schofield et al. 2018). Each AUP is isolated from other analogous natural or anthropogenic water basins and from natural streams. Since water depth of AUPs ranged from 1 to $1.30 \mathrm{~m}$, we considered comparable these ponds and not stratified data for this variable.

\section{Protocol}

For each AUP, we measured area size (A, in ha) and distance (Dist, in $\mathrm{m}$ ) from the nearest road (Google Earth 5.1 software). For the smallest ponds $(<0.01 \mathrm{ha})$, the radius was calculated (measuring tape Komelon \# $1 \mathrm{~cm}$; max length $3.5 \mathrm{~m}$ ). Since we obtained a significant direct correlation between A and Dist ( $r=0.224, p<0.001)$, it was only A that we considered to be a predictor variable.

We carried out a periodic sampling of each pond from July to September 2009, walking along their shores. Research effort was proportional to area size, ranging from 30 min for the smallest to 2 hours for the largest AUPs (total research effort: approximately $300 \mathrm{~h}$ of sampling). All fish were captured and subsequently released after taxonomic diagnosis using a professional fishing sieve in Nylon Mesh Scoop of circular shape $(50 \times 50 \mathrm{~cm})$; mesh size (similar throughout the net): $30 \mathrm{~mm}$, with a $2 \mathrm{~m}$ stiff rod, following the techniques used for freshwater environments in human-transformed landscapes (e.g. Fialho et al. 2008). Fish individuals were recorded for each pond, carrying out a systematic, replicated and representative sampling design (two transects located along the main axes and the edge of each AUP). We referred to Kottelat and Freyhof (2007) for taxonomic diagnosis of specimens.
For each AUP, we obtained the number of fish species (S) as a dependent variable, calculating the log-transformed species-area relationship for all the AUPs as:

$$
\log \mathrm{S}=z \log \mathrm{A}+\mathrm{c}
$$

where $\mathrm{S}=$ number of fish species, $\mathrm{A}=$ area size, $z$ and $\mathrm{c}=$ coefficients $(z$ value corresponding to the steepness of the linear fit).

The log-log transformation has been the most common transformation used in the literature to describe the species-area relationship because of its higher explanatory power (Watling and Donnelly 2006).

To search for size thresholds, we grouped AUPs into four log-based classes of size (I: $<0.01 \mathrm{ha} ; \mathrm{n}=235$; II: $>0.01-0.1 ; n=41 ;$ III: $>0.1-1 ; n=28 ;$ IV: $>1, n=7$ ), calculating, for each of them, the mean number $\left(\mathrm{S}_{\text {mean }}\right.$, and standard deviation) of species. For each species, we obtained the frequency of occurrence (i.e. number of AUP occurrences of each species/total number of species occurrences).

A diversity-dominance analysis was carried out (Whittaker plots; Dornelas et al. 2011), utilizing the data set (species rank-frequency) for the four size class assemblages, obtaining a first-degree equation for each class $(F r=a r+b)$, where $F r=$ frequency of occurrence in each size class assemblage, $r=$ species rank, $a=$ angular coefficient of regression line, $b=$ intercept value. The shape and slope of regression lines, obtained by comparing the rank and frequency of species, allow to infer the response to anthropogenic or natural stresses (a high slope of the assemblage line indicating anthropogenic or natural stresses as in resource-poor environments or when strong disturbances have occurred: Dornelas et al. 2011).

We performed a two-tailed Pearson test to assess the significance of the relationship between log-transformed pond size and the number of species, and Mann-Whitney $\mathrm{U}$ and Kruskal-Wallis tests for comparing $\mathrm{S}_{\text {mean }}$ values. We performed a heterogeneity slopes test (one-way ANCOVA) among rank-frequency relationships. We used the SPSS 11.5 for Windows software. Alfa was set at 0.5 .

\section{RESULTS}

We detected 10 fish species (all introduced) in 40 AUPs (12.9\%; $\mathrm{n}=311$; Supplementary material S1). The most widespread species were Carassius auratus, Cyprinus carpio and Gambusia holbrooki (Table 1). The $\log$-transformed species-area relationship $(\log \mathrm{S}=$ $0.04 \log \mathrm{A}+0.16)$ was significant $(r=0.295, p<0.001)$, but with a high variance $\left(\mathrm{R}^{2}=0.09\right)$ and a low $z$ value 
(0.04). We observed a significant difference in the mean number of species among size classes $\left(\chi^{2}=43.040\right.$, $p<0.001$, d. f. 3; Kruskall-Wallis test) with thresholds when comparing either the two smallest $(<0.01-0.01$ vs. $0.01-0.1 ; \mathrm{U}=4138.5, \mathrm{Z}=-2.749, p=0.006)$ or the largest size classes $(0.01-1 v s .>1: \mathrm{U}=39, \mathrm{Z}=-2.881$, $p=0.004$; Mann-Whitney U test). We did not observe significant differences when comparing 0.01-0.1 and $0.1-1$ classes $(\mathrm{U}=569.5, \mathrm{Z}=-0.076, p=0.939$; MannWhitney U test).

We observed significant differences between equation lines in diversity-dominance analysis (heterogeneity of slopes test: $\mathrm{F}=3.337, p<0.05$ ), with the smallest size assemblages showing the highest slope (Fig. 1).

\section{DISCUSSION}

Our mosaic of anthropogenic urban ponds hosts about $10 \%$ of the total of Italian freshwater fish species (101 species: 50 native and 51 non-native; Bianco 2014). All these species have been surely introduced into our study areas, since our ponds were artificially built with no linkage with the local hydrographic system. Moreover, the diversity of introductions is underestimated in the present manuscript, which makes no mention of the goldfish varieties involved (see Omori and Kon 2018). Therefore, this fish assemblage represents a large-scale example of non-native diversity (= xenodiversity) in an urban landscape (see Gherardi et al. 2008, for an arrangement).

Only $13 \%$ of urban ponds contained fishes. The occupancy rate in the Rome area, therefore, seems to be rather low. The fact that these are urban, humanmanaged ponds means that 'extinction' can be either due to natural mortality or human removal of fish (i.e. human-mediated extinction), either killed or released into public water bodies for disposal - a phenomenon discussed in Copp et al. (2005).

We observed a weak positive species-area relationship for this introduced fish assemblage. However, $z$ value was extremely low when compared to other mainland 'archipelagos' (review in Watling and Donnelly 2006). Since this coefficient shows the biological meaning with respect to taxon-perceived isolation (lower $z$ values indicating high immigration rates), we can hypothesize

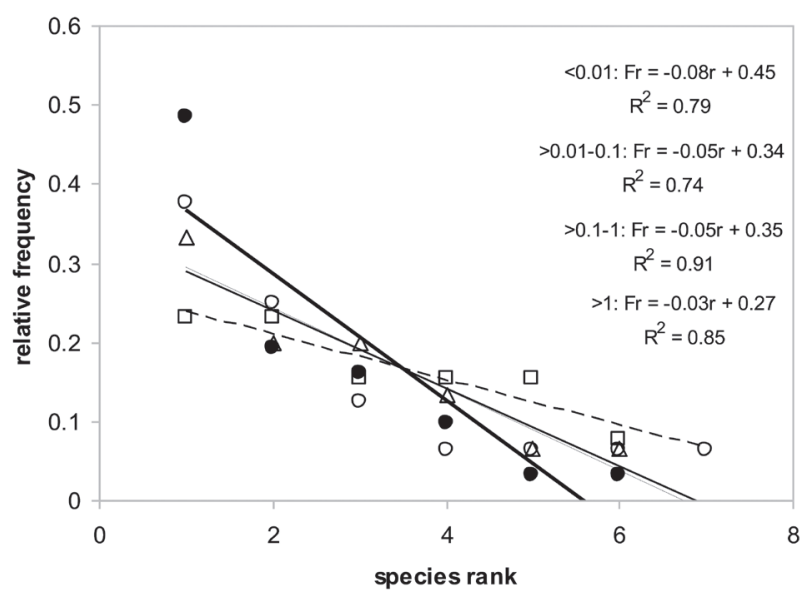

Figure 1. Species rank-relative frequency (or diversitydominance) diagram for the four size-based fish assemblages (species rank, $\mathrm{x}$ axis, vs. relative frequency of occurrence, $\mathrm{y}$ axis). Black points and bold line: $<0.01$ ha size class; white circles and continuous line: $>0.01-0.1$; triangles and pointed line: $>0.1-1$; squares and dashed line: $>1$. Regression line and coefficient of determination $\mathrm{R}^{2}$ was also reported.

Table 1. Number (and percentage, \%) of introduced fish species occurrences in the study area for the total of AUPs $(n=311)$ and for the sub-sample of AUPs with at least one species $(n=40)$. For each AUP size class, the number of occurrences and relative frequency of occurrence were also reported. $\mathrm{N}$ occ: number of occurrence of species in each AUP size class; Fr: relative frequency of species; \% (total): percentage on the total of AUPs $(n=311) ; \%$ (sub-sample): percentage considering only the AUPs with at least one fish species $(n=40)$. Mean number of species (and standard deviation, s. d.) for each AUP size class is reported.

\begin{tabular}{|c|c|c|c|c|c|c|c|c|c|c|c|}
\hline & \multirow{3}{*}{$\mathrm{N}$ occ } & \multirow{3}{*}{$\begin{array}{c}\% \\
\text { (total) }\end{array}$} & \multirow{3}{*}{$\begin{array}{c}\% \text { (sub } \\
\text { sample) }\end{array}$} & \multicolumn{8}{|c|}{ AUP size classes } \\
\hline & & & & \multicolumn{2}{|c|}{$<0.01$} & \multicolumn{2}{|c|}{$>0.01 .-0.1$} & \multicolumn{2}{|c|}{$>0.1-1$} & \multicolumn{2}{|c|}{$>1$} \\
\hline & & & & $\mathrm{N}$ occ & $\mathrm{Fr}$ & $\mathrm{N}$ occ & $\mathrm{Fr}$ & $\mathrm{N}$ occ & $\mathrm{Fr}$ & $\mathrm{N}$ occ & $\mathrm{Fr}$ \\
\hline Carassius auratus & 25 & 8.04 & 62.5 & 15 & 0.484 & 6 & 0.375 & 2 & 0.133 & 2 & 0.154 \\
\hline Cyprinus carpio & 17 & 5.47 & 42.5 & 5 & 0.161 & 4 & 0.250 & 5 & 0.333 & 3 & 0.231 \\
\hline Gambusia holbrooki & 12 & 3.86 & 30 & 6 & 0.194 & 2 & 0.125 & 1 & 0.067 & 3 & 0.231 \\
\hline Squalius squalus & 5 & 1.61 & 12.5 & 3 & 0.097 & 1 & 0.063 & 0 & 0 & 1 & 0.077 \\
\hline Micropterus salmoides & 5 & 1.61 & 12.5 & 0 & 0 & 0 & 0 & 3 & 0.2 & 2 & 0.154 \\
\hline Lepomis gibbosus & 5 & 1.61 & 12.5 & 0 & 0 & 0 & 0 & 3 & 0.2 & 2 & 0.154 \\
\hline Carassius carassius & 2 & 0.64 & 5 & 1 & 0.032 & 1 & 0.063 & 0 & 0 & 0 & 0 \\
\hline Rutilus rubilio & 2 & 0.64 & 5 & 1 & 0.032 & 1 & 0.063 & 0 & 0 & 0 & 0 \\
\hline Padogobius nigricans & 1 & 0.32 & 2.5 & 0 & 0 & 0 & 0 & 1 & 0.067 & 0 & 0 \\
\hline Ameiurus melas & 1 & 0.32 & 2.5 & 0 & 0 & 1 & 0.063 & 0 & 0 & 0 & 0 \\
\hline \multicolumn{4}{|c|}{ Mean number of species (and s. d) } & \multicolumn{2}{|c|}{$0.13(0.51)$} & \multicolumn{2}{|c|}{$0.39(0.83)$} & \multicolumn{2}{|c|}{$0.54(1.23)$} & \multicolumn{2}{|c|}{$1.86(1.95)$} \\
\hline
\end{tabular}


that the absence of natural dispersal in these totally introduced assemblages that occurred in our isolated artificial ponds could be overpassed by a continuous and arbitrary anthropogenic introduction (a case of human-mediated immigration); therefore, the fish species richness in these contexts might depend exclusively on (i) random anthropogenic introductions by citizens and (ii) progressive extinctions (due to a limited suitable area, low resource availability, active removal by humans, and periodic events of water stress for pond management - the latter suggested as a disturbance affecting introduced fish populations: Freeman and Marcinek 2006). In this regard, the classic immigration-extinction processes could be here represented by introduction-extinction processes. Ryan et al. (2008) and Di Santo et al. (2017) yet introduced the hypothesis that species-area patterns could be explained more effectively from introduction/extinction mechanisms in the mosaics of urban ponds when compared to classic immigration/extinction processes. However, this interpretation allowed us to postulate an a-posteriori hypothesis that should be tested in future research (inductive approach: Guthery 2007).

We observed a significant threshold in the mean number of species between two smallest size classes $(<0.01 v s$. $0.01-0.1$ ). Analogously, water basins $>1$ ha showed a significantly higher number of species when compared to smaller ponds (size class: $0.1-1$ ): these thresholds could represent an interesting threshold for urban pond management. First, the smallest anthropogenic ponds cannot support fish assemblages; second, only the largest ponds ( $>1$ ha) can host a representative set of species.

The first evidence of pond size effect acting as a spatial factor of stress has been obtained applying the diversitydominance approach to these peculiar fish assemblages. The change in line slopes showed the progressive disruption in its structure, thus indicating a stress. In this sense, the 'pond size' variable could be considered a proxy of suitable factors allowing the persistence of fish populations. Area size as a stressor on animal assemblages has been observed using diversity-dominance approaches only in birds (Battisti et al. 2009), and this is one of the first studies that applied this approach to assemblages constituted only of introduced species. However, the relationships between species richness, access proximity and pond area have been yet observed: for example, Copp et al. (2005) regarding ornamental and aquarium fish introductions into urban ponds suggested that these artificial ecosystems are selected (by the general public) for the introduction of fish according to two main factors: proximity and size.

It has been highlighted that urban ponds, when correctly managed, might act as important sites of conservation for native fish species (Copp et al. 2008) and as a surrogate compensating for wetland loss at a regional scale (Semlitsch and Bodie 1998; Gibbs 1993, 2000; Leibowitz 2003). We improved this statement suggesting that, although the introduction of fish species in urban ponds should be carefully limited and controlled since they represent the driving forces inducing habitat changes and homogenization (Scott and Helfman 2001; Duggan et al. 2006; Dar and Reshi 2014); however, in urbanized contexts that lack native species they could represent a paradoxical ecosystem service being the only experiential (and charismatic) targets for new urban generations living in anthropized environments (Battisti et al. 2018).

Our study has some limitations since it focused only on the relationships between two important spatial variables (area and distance from the road), assumed as predictors of the presence and persistence of fish assemblages over time. Another important parameter, the depth of the ponds, which shows a limited range (1-1.50 $\mathrm{m}$ in depth) in our sample was considered approximately constant and comparable, similarly to the origin of the ponds (all anthropogenic). However, many other environmental variables not considered here can affect the presence and persistence over time of fish species and assemblages (e.g. vegetation overgrowth and shading, water retention time together with oxygen saturation and maximum temperature values in summer). Therefore, although a spatial pattern is evident, this can be considered only a first spatially based arrangement, and further researches will be able to investigate the role of other non-spatial ecological variables.

\section{ACKNOWLEDGEMENTS}

We wish to thank Alex Zocchi for the English revision. Two anonymous reviewers and the Editor provided useful suggestions and comments.

\section{DISCLOSURE STATEMENT}

No potential conflict of interest was reported by the authors.

\section{ORCID 0000-0002-2621-3659}

\section{REFERENCES}

Báldi, A. 2008. Habitat heterogeneity overrides the species-area relationship. Journal of Biogeography 35: 675-681. 
Battisti, C., L. Luiselli, B. Frank, and E. Lorenzetti. 2009. Should fragment area reduction be considered a stress for forest bird assemblages? Evidence from diversity/dominance diagrams. Community Ecology 10: 189-195.

Battisti, C., G. Fanelli, S. Bertolino, L. Luiselli, G. Amori, and S. Gippoliti. 2018. Non-native invasive species as paradoxical ecosystem services in urban conservation education. Web Ecology 18: 37-40.

Benassi, G., C. Battisti, and L. Luiselli. 2007. Area effect on bird species richness of an archipelago of wetland fragments of Central Italy. Community Ecology 8: 229-237.

Bianco, P. G. 2014. An update on the status of native and exotic freshwater fishes of Italy. Journal of Applied Ichthyology 30: 62-77.

Boecklen, W. J. 1986. Effects of habitat heterogeneity on the species-area relationships of forest birds. Journal of Biogeography 13: 59-68.

Copp, G. H., K. J. Wesley, and L. Vilizzi. 2005. Pathways of ornamental and aquarium fish introductions into urban ponds of Epping Forest (London, England): the human vector. Journal of Applied Ichthyology 21: 263-274.

Copp, G. H., S. Warrington, and K. J. Wesley. 2008. Management of an ornamental pond as a conservation site for a threatened native fish species, crucian carp Carassius carassius. Hydrobiologia 597: 149-155.

Dar, P. A., and Z. A. Reshi. 2014. Components, processes and consequences of biotic homogenization: A review. Contemporary Problems in Ecology 7: 123-136.

Di Santo, M. P., G. M. Carpaneto, and C. Battisti. 2015. Water-related bird assemblages in an urban pond 'archipelago': Winter patterns of bird species occurrence, abundance and richness. Lakes Reservoirs: Research and Management 20: 33-41.

Di Santo, M. P., L. Vignoli, G. M. Carpaneto, and C. Battisti. 2017. Occurrence patterns of alien freshwater turtles in a large urban pond 'archipelago' (Rome, Italy): Suggesting hypotheses on root causes. Lakes and Reservoirs: Research and Management 22: 56-64.

Dornelas, M., C. U. Soykan, and K. I. Ugland. 2011. Biodiversity and disturbance. In Biological diversity. Frontiers in measurements and assessments, edited by Magurran A., McGill B. J., 237-251. Oxford: Oxford University Press.

Duggan, I. C., C. A. M. Rixon, and H. J. MacIsaac. 2006. Popularity and propagule pressure: determinants of introduction and establishment of aquarium fish. Biological Invasions 8: 393-398.

Fialho, A. P., L. G. Oliveira, F. L. Tejerina-Garro, and B. de Mérona. 2008. Fish-habitat relationship in a tropical river under anthropogenic influences. Hydrobiologia 598: 315-324.

Freeman, M. C., and P. A. Marcinek. 2006. Fish assemblage responses to water withdrawals and water supply reser- voirs in piedmont streams. Environmental Management 38: $435-450$.

Gherardi, F., S. Bertolino, M. Bodon, S. Casellato, S. Cianfanelli, M. Ferraguti, E. Lori, G. Mura, A. Nocita, N. Riccardi, G. Rossetti, E. Rota, R. Scalera, S. Zerunian, and E. Tricarico. 2008. Animal xenodiversity in Italian inland waters: distribution, mode of arrival, and pathways. Biological Invasions 10: 435-454.

Gibbs, J. P. 1993. Importance of small wetlands for the persistence of local populations of wetland-associated animals. Wetlands 13: 25-31.

Gibbs J. P. 2000. Wetland loss and biodiversity conservation. Conservation Biology 14: 314-317.

Godefroid, S., and N. Koedam. 2003. How important are large $v s$. small forest remnants for the conservation of the woodland flora in an urban context? Global Ecology and Biogeography 12: 287-298.

Guthery, F. S. 2007. Deductive and inductive methods of accumulating reliable knowledge in wildlife science. Journal of Wildlife Management 71: 222-225.

Hassall, C. 2014. The ecology and biodiversity of urban ponds. Water 1: 187-206.

Hill, M. J., J. Biggs, I. Thornhill, R. A. Briers, D. G. Gledhill, J. C. White, P. J. Wood, and C. Hassall. 2017. Urban ponds as an aquatic biodiversity resource in modified landscapes. Global Change Biology 23: 986-999.

Kalmar, A., and D. J. Currie. 2006. A global model of island biogeography. Global Ecology and Biogeography 15: 72-81.

Kitchener, D. J., A. Chapman, J. Dell, and B. G. Muir. 1980. Lizard assemblage and reserve size and structure in the Western Australian wheat belt - some implications for conservation. Biological Conservation 17: 25-62.

Kottelat, M., and J. Freyhof. 2007. Handbook of European freshwater fishes. Berlin: Publications Kottelat, Cornol, Switzerland, and Freyhof.

Leibowitz, S. G. 2003. Isolated wetlands and their functions: an ecological perspective. Wetlands 23: 517-531.

MacArthur, R. H., and E. O. Wilson. 1967. The theory of island biogeography. Princeton: Princeton Univ. Press.

Magurran, A. E. 2004. Measuring Biological Diversity. New York: Blackwell Publishing.

Martınez-Arroyo, A., and E. Jauregui. 2000. On the environmental role of urban lakes in Mexico City. Urban Ecosystems 4: 145-166.

Oberdorff, T., P. A. Tedesco, B. Hugueny, F. Leprieur, O. Beauchard, S. Brosse, and H. H. Dürr. 2011. Global and regional patterns in riverine fish species richness: a review. International Journal of Ecology 967-631.

Omori, Y., and T. Kon. 2018. Goldfish: an old and new model system to study vertebrate development, evolution and human disease. Journal of Biochemistry 165: 209-218.

Ryan, T. J., C. A. Conner, B. A. Douthitt, S. C. Sterrett, and C. M. Salsbury. 2008. Movement and habitat use of two 
aquatic turtles (Graptemys geographica and Trachemys scrypta) in an urban landscape. Urban Ecosystems 11: 213-225.

Schofield, K. A., L. C. Alexander, C. E. Ridley, M. K. Vanderhoof, K. M. Fritz, B. C. Autry, J. E. DeMeester, W. G. Kepner, C. R. Lane, S. G. Leibowitz, and A. I. Pollard. 2018. Biota connect aquatic habitats throughout freshwater ecosystem mosaics. JAWRA Journal of the American Water Resources Association 54: 372-399.

Scott, M. C., and G. S. Helfman. 2001. Native invasions, homogenization, and the mismeasure of integrity of fish assemblages. Fisheries 26: 6-15.

Semlitsch, R. D., and J. R. Bodie. 1998. Are small, isolated wetlands expendable? Conservation Biology 12: 1129-1133.

Soule, M. E., and D. Simberloff. 1986. What do genetics and ecology tell us about the design of nature reserves? Biological Conservation 35: 19-40.

Spellerberg, I. F., and J. W. D. Sawyer. 1999. An Introduction to Applied Biogeography. Cambridge: Cambridge University Press.

Stein, A., K. Gerstner, and H. Kreft. 2014. Environmental heterogeneity as a universal driver of species richness across taxa, biomes and spatial scales. Ecology Letters 17: 866-880.

Watling, J. I., and M. A. Donnelly. 2006. Fragments as islands: a synthesis of faunal responses to habitat patchiness. Conservation Biology 20: 1016-1025.

Zhang, C., J. Wu, N. B. Grimm, M. McHale, and A. Buyantuyev. 2013. A hierarchical patch mosaic ecosystem model for urban landscapes: model development and evaluation. Ecological Modelling 250: 81-100.

\section{Supplementary materials}

S1 Fish species of the study area. A: non-native for Italian freshwaters; N: native for Italian freshwaters, but all introduced into the studied artificial urban ponds (AUPs).

\begin{tabular}{|l|l|l|l|}
\hline \multicolumn{1}{|c|}{ Species } & \multicolumn{1}{c|}{ Fnglish name } & \multicolumn{1}{c|}{ Distribution } \\
\hline Carassius auratus (Linnaeus, 1758) & Goldfish & Cyprinidae & A \\
\hline Carassius carassius (Linnaeus, 1758) & Crucian carp & Cyprinidae & A \\
\hline Cyprinus carpio Linnaeus, 1758 & European carp & Cyprinidae & A \\
\hline Rutilus rubilio (Bonaparte, 1837) & South European roach & Cyprinidae & N \\
\hline Squalius squalus (Linnaeus 1758) & Italian chub & Cyprinidae & N \\
\hline Ameiurus melas (Rafinesque, 1820) & Black bullhead catfish & Ictaluridae & A \\
\hline Micropterus salmoides (Lacépède, 1802) & Largemouth bass & Centrarchidae & A \\
\hline Lepomis gibbosus (Linnaeus, 1758) & Pumpkinseed & Centrarchidae & A \\
\hline Gambusia holbrooki Girard, 1859 & Eastern mosquitofish & Poecilidae & A \\
\hline Padogobius nigricans (Canestrini, 1867) & Arno goby & Gobiidae & N \\
\hline
\end{tabular}

